\title{
DIVERSIDADE EM MODULAÇÃO APLICADA A CANAIS DE COMUNICAÇÕES MÓVEIS
}

\author{
Waslon Terllizzie A. Lopes, Juraci F. Galdino e Marcelo S. Alencar
}

\begin{abstract}
Resumo - O desempenho de sistemas de comunicações móveis pode ser significativamente melhorado por meio do uso da técnica de diversidade em modulação, que consiste basicamente na combinação da escolha criteriosa do ângulo de referência de uma constelação MPSK com o entrelaçamento independente das componentes dos símbolos transmitidos. Considerando a ausência de erros de estimação no receptor, esta técnica apresenta um bom desempenho quando o canal de comunicações está sujeito aos efeitos do desvanecimento plano. Neste artigo, o desempenho desta recente técnica é analisado levando em consideração a presença de erros de estimação da resposta impulsiva do canal. Mostra-se, por meio de simulações, que a técnica é eficaz mesmo sob esta condição. Adicionalmente, o impacto do efeito Doppler no desempenho do sistema é tratado, sendo estabelecido um compromisso entre a profundidade de entrelaçamento utilizada e a probabilidade de erro do sistema.
\end{abstract}

Palavras-chave: Comunicações móveis, desvanecimento plano, diversidade em modulação, entrelaçamento, estimação de canal.

\begin{abstract}
The performance of mobile communications systems can be significantly improved by using the modulation diversity technique which is, basically, based on the combination of a suitable choice of the reference angle of an MPSK constellation with independent interleaving of the symbols components. This technique presents good performance assuming the absence of estimation errors for channels characterized by the flat fading. In this article, the performance of that recent technique is analyzed taking into account the effects of channel estimation errors. It is shown, by simulation, that the efficiency of this technique is maintained even under this assumption. Additionally, the impact of the Doppler effect on the system performance is treated and a trade-off between the interleaving depth used and the error probability is achieved.
\end{abstract}

Keywords: Mobile communications, flat fading, modulation diversity, interleaving, channel estimation.

Waslon Terllizzie Araújo Lopes e Marcelo Sampaio de Alencar estão vinculados ao Laboratório de Comunicações, Departamento de Engenharia Elétrica, Universidade Federal da Paraíba, Campina Grande, PB, Brasil. Juraci Ferreira Galdino está vinculado ao Departamento de Engenharia Elétrica, Instituto Militar de Engenharia, Rio de Janeiro, RJ, Brasil. E-mails: \{waslon,malencar\}@dee.ufpb.br, galdino@dee.ufpb.br. Editor de Área responsável: Renato Baldini Filho. Artigo submetido em 20/Nov/2001, revisado em 13/Fev/2002, aceito em 20/Mar/2002.

\section{INTRODUÇÃO}

O efeito do desvanecimento, provocado pelos múltiplos percursos de propagação dos sinais transmitidos em canais de comunicações móveis, pode degradar significativamente o desempenho de sistemas de comunicações digitais. Em razão disto, várias técnicas vêm sendo propostas para melhoria de desempenho desses sistemas. Dentre elas, podem ser citadas técnicas de diversidade [1-6], esquemas de modulação codificada [7, 8], e uso da transformada wavelet na codificação [9].

Em particular, as técnicas de diversidade consistem, basicamente, em gerar redundância (réplicas) do sinal transmitido no receptor. Exemplos típicos de técnicas de diversidade são: diversidade temporal, diversidade em frequiência e diversidade espacial $[3,5]$. Outro método de diversidade proposto recentemente consiste em introduzir redundância por meio de uma escolha criteriosa do ângulo de referência de uma constelação MPSK combinada com o entrelaçamento independente das componentes do símbolos a serem transmitidos [10-15]. No presente artigo, esta técnica será denominada de diversidade em modulação.

A Figura 1 mostra como o desempenho de um sistema pode ser afetado pela escolha do ângulo de referência de uma constelação QPSK quando o canal de comunicações está sujeito aos efeitos do desvanecimento. Nesta figura os círculos cheios representam a constelação no transmissor, ao passo que os círculos vazios indicam a constelação na entrada do receptor. Como pode ser observado, apenas a componente em quadratura do símbolo transmitido é atingida por um pico de desvanecimento. Pode-se notar que a constelação "comprimida" apresentada na Figura 1(b) (círculos vazios) oferece mais proteção contra os efeitos do ruído do que a constelação apresentada na Figura 1(a), porque dois símbolos distintos não colidem pois apresentam projeções distintas nos eixos em fase $(I)$ e em quadratura $(Q)$ [12].

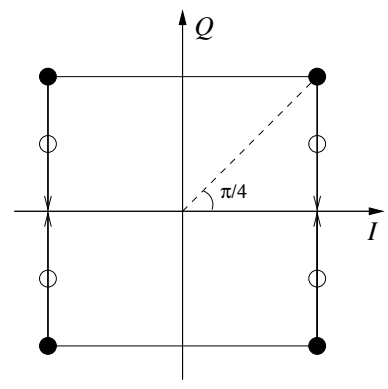

(a) Sem diversidade.

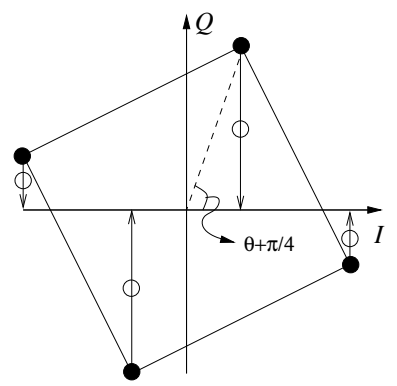

(b) Com diversidade.
Figura 1. Efeito do desvanecimento sobre uma constelação QPSK: símbolos transmitidos $(\bullet)$ e símbolos recebidos (०). 
$\mathrm{Na}$ realidade, o desvanecimento afeta aleatoriamente as componentes em fase e em quadratura dos sinais transmitidos e a situação apresentada na Figura 1 contempla apenas um caso particular. Contudo, verifica-se que a probabilidade de ocorrência conjunta de dois picos de desvanecimento é praticamente nula em canais independentes [16]. Sendo assim, admitindo que as componentes em fase e em quadratura são afetadas de forma independente, pode-se verificar que, na média, a constelação com diversidade é mais adequada para a transmissão neste tipo de canal.

Na prática, para garantir a independência entre o desvanecimento sofrido pelas componentes em fase e em quadratura podem-se utilizar múltiplas antenas [1] ou entrelaçamento independente de componentes [11]. A utilização de múltiplas antenas apresenta o inconveniente de não poder ser utilizada de forma eficaz no terminal móvel. De fato, devido a limitações de dimensão no terminal móvel (proximidade entre as antenas) é difícil obter independência entre os percursos que chegam em cada antena. Por sua vez, o entrelaçamento independente de componentes apresenta a vantagem de poder ser utilizado tanto na estação rádio-base quanto no terminal móvel. No entanto, esta última abordagem apresenta a desvantagem de introduzir atraso no sistema.

Em [15], considerando-se canais sujeitos ao desvanecimento do tipo Rayleigh, mostrou-se que a diversidade em modulação leva a um ganho de desempenho do sistema, em termos da probabilidade de erro de bit, por meio da escolha criteriosa do ângulo de referência de uma constelação QPSK. No entanto, os resultados obtidos em [15] consideravam o canal descorrelacionado (freqüência Doppler infinita) e a ausência de erros de estimação de canal no receptor, que constitui uma suposição bastante restritiva na prática. $\mathrm{O}$ efeito dos erros de estimação da resposta impulsiva (RI) do canal no desempenho de sistemas que empregam diversidade em modulação foi analisado em [17], no qual se utilizou o limitante de Cramér-Rao [18] na determinação da variância do erro de estimação no esquema proposto. A análise apresentada em [17], apesar de válida, não contemplou alguns aspectos importantes como a propagação dos erros de decisão e a influência do efeito Doppler nos erros de estimação da RI do canal.

No presente artigo, o esquema proposto em [11] é analisado levando em consideração a presença de erros de estimação da RI do canal. Mais especificamente, considerase a aplicação do algoritmo LMS (Least Mean Square) e a utilização de um PLL (Phase-Lock Loop) de 1a ordem para o acompanhamento do módulo e da fase do canal de comunicação, respectivamente. Adicionalmente, um outro aspecto bastante importante para o desempenho do sistema o grau de correlação entre os coeficientes do desvanecimento (medido em termos da máxima freqüência Doppler) é tratado, tendo em vista a minimização dos requisitos de memória e atraso do sistema [19]. Vale ressaltar que o presente trabalho difere significativamente de [17], no qual não é considerada a implementação de um algoritmo de estimação específico.

$\mathrm{O}$ restante deste artigo encontra-se organizado da seguinte forma. A Seção 2 apresenta o modelo do sistema utilizado e os princípios básicos da diversidade em modulação aplicada a canais com desvanecimento. Os algoritmos de estimação implementados são descritos na Secão 3. Na Seção 4 são apresentados e comentados os resultados de simulações. Finalmente, a Seção 5 é destinada às conclusões.

\section{O MODELO DO SISTEMA}

A modulação QPSK pode ser vista como duas modulações PSK binárias em paralelo - uma em fase $(I)$ e outra em quadratura $(Q)$. Os dois sinais correspondentes são ortogonais e podem ser separados no receptor. Neste esquema, o sinal transmitido é dado por

$$
\begin{aligned}
s(t) & =A \sum_{n=-\infty}^{+\infty} a_{n} p\left(t-n T_{S}\right) \cos \left(\omega_{c} t\right) \\
& +A \sum_{n=-\infty}^{+\infty} b_{n} p\left(t-n T_{S}\right) \operatorname{sen}\left(\omega_{c} t\right)
\end{aligned}
$$

sendo

$$
\begin{gathered}
a_{n}, b_{n}= \pm 1 \quad \text { com mesma probabilidade, } \\
p(t)= \begin{cases}1, & 0 \leq t \leq T_{S} \\
0, & \text { caso contrário }\end{cases}
\end{gathered}
$$

em que $\omega_{c}$ e $A$ são a freqüência e amplitude da portadora respectivamente.

Pode ser observado, a partir da Equação 1, que a informação transmitida em uma componente é independente da informação transmitida na outra. Além do mais, a transmissão destes sinais em canais com desvanecimento independente pode introduzir um ganho de diversidade se houver redundância entre as duas componentes.

A introdução de redundância no esquema QPSK pode ser realizada combinando-se a escolha criteriosa do ângulo de referência da constelação de sinais por uma fase constante $\theta$, como mostrado na Figura 2, com o entrelaçamento independente das componentes [11]. Para essa constelação girada, o sinal transmitido pode ser escrito como

$$
\begin{array}{r}
s(t)=A \sum_{n=-\infty}^{+\infty} x_{n} p\left(t-n T_{S}\right) \cos \left(\omega_{c} t\right) \\
+A \sum_{n=-\infty}^{+\infty} y_{n-k} p\left(t-n T_{S}\right) \operatorname{sen}\left(\omega_{c} t\right)
\end{array}
$$

sendo $k$ um inteiro representando o atraso (expresso em número de símbolos) introduzido pelo entrelaçamento entre as componentes $I$ e $Q$. Além disso,

$$
x_{n}=a_{n} \cos \theta-b_{n} \operatorname{sen} \theta
$$

$\mathrm{e}$

$$
y_{n}=a_{n} \operatorname{sen} \theta+b_{n} \cos \theta
$$

são os novos símbolos QPSK $^{1}$. O diagrama de blocos do transmissor que implementa este procedimento é apresentado na Figura 3.

\footnotetext{
${ }^{1}$ É importante observar que, na prática, os bits de entrada podem ser mapeados diretamente na constelação girada, sem a necessidade de implementar as expressões da Equação (3).
} 


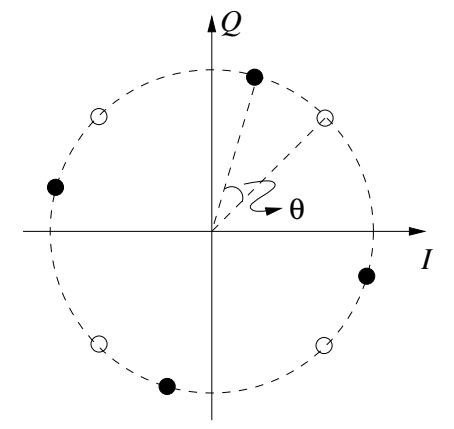

Figura 2. Constelação QPSK: referência (o) e girada por um ângulo $\theta(\bullet)$.

O ganho de desempenho desta técnica fundamenta-se no seguinte raciocínio. Como os picos de desvanecimentos são profundos, mas de curta duração, eles podem degradar toda informação (componentes em fase e em quadratura de um símbolo) numa transmissão convencional. Isto dificilmente ocorrerá no esquema proposto, pois as componentes de um símbolo são transmitidas em instantes de tempo distintos e existe redundância entre as componentes em fase e quadratura.

Uma característica interessante desse esquema é que o valor de $\theta$ não influencia o desempenho do sistema quando os sinais transmitidos são afetados apenas pelo ruído gaussiano branco (canal AWGN), pois a distância Euclidiana entre os símbolos da constelação não depende do ângulo $\theta$. Observase também que a eficiência espectral do sistema é mantida porque a cada intervalo de sinalização 2 bits são transmitidos independentemente do valor de $\theta$. Além do mais, a complexidade deste esquema é relativamente baixa, pois requer apenas a adição de entrelaçadores ao transmissor, uma vez que os bits de entrada podem ser mapeados diretamente na constelação desejada. Por sua vez, haverá um aumento de complexidade no receptor em virtude de os estimadores de canal utilizarem um número maior de regiões de decisão. No caso da constelação QPSK, no método proposto têm-se um total de $4 \times 4=16$ regiões de decisão, ao passo que num esquema convencional têm-se apenas 4 regiões de decisão.

Assumindo que o canal de comunicações móveis é caracterizado por desvanecimento rápido e plano, o sinal recebido, aqui denotado por $r(t)$, é dado por

$$
r(t)=\alpha(t) s(t)+\eta(t)
$$

em que $\eta(t)$ representa o ruído aditivo modelado por um processo gaussiano branco, complexo, com média nula e variância $N_{0} / 2$ por dimensão. Além disso, o fator multiplicativo $\alpha(t)$ é modelado por um processo gaussiano estacionário em sentido amplo com densidade espectral de potência (DEP) dada por

$$
G(f)= \begin{cases}\frac{1}{\sqrt{1-\left(\frac{f}{f_{D}}\right)^{2}}}, & \text { se }|f|<f_{D} \\ 0, & \text { se }|f| \geq f_{D}\end{cases}
$$

em que $f_{D}$ é o máximo desvio Doppler [20]. O Método de Monte Carlo, descrito no Apêndice, foi utilizado para geração da variável aleatória $\alpha(t)$.

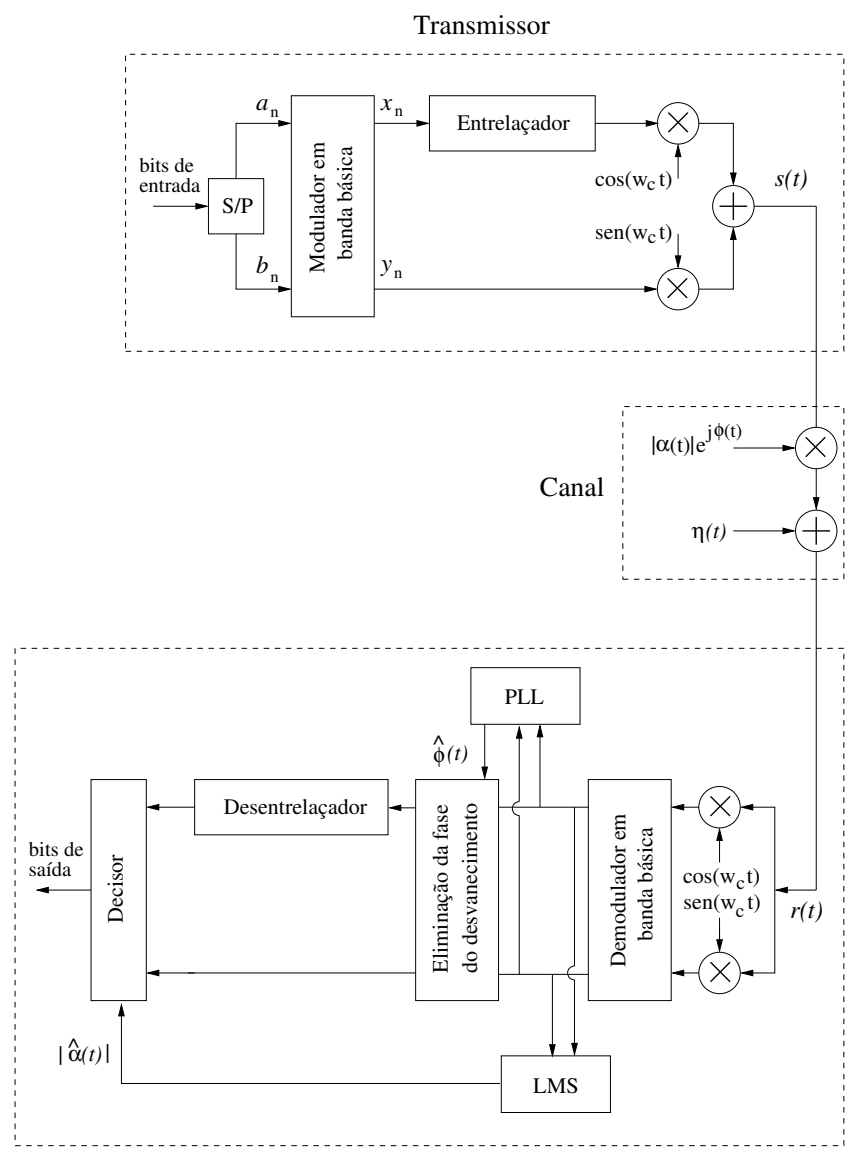

Receptor

Figura 3. Diagrama de blocos do sistema simulado.

A função de autocorrelação referente a esta DEP é dada por

$$
R_{\boldsymbol{\alpha} \boldsymbol{\alpha}}(T)=\frac{1}{2} E\left\{\boldsymbol{\alpha}^{*}(t) \boldsymbol{\alpha}(t+T)\right\}=J_{0}\left(2 \pi f_{D} T\right),
$$

em que $J_{0}(\cdot)$ é a função de Bessel de ordem zero e $T$ é o tempo de separação entre as amostras. O gráfico desta função de autocorrelação é mostrada na Figura 4 considerando uma freqüência de amostragem igual a 24,3 kbauds e $f_{D}$ igual a $50 \mathrm{~Hz}, 100 \mathrm{~Hz}$ e $150 \mathrm{~Hz}$.

No receptor (Figura 3), $r(t)$ é inicialmente convertido para banda básica. O sinal obtido $r_{n}(t)$ (equivalente passa-baixas) em um intervalo de sinalização é

$$
\begin{gathered}
r_{n}(t)=\left|\boldsymbol{\alpha}_{n}(t)\right| e^{j \phi_{n}(t)} s_{n}(t)+\eta_{n}(t), \\
n T_{s} \leq t \leq(n+1) T_{s},
\end{gathered}
$$

em que $\eta_{n}(t)$ representa o ruído gaussiano branco complexo, $\left|\boldsymbol{\alpha}_{n}(t)\right|$ denota a amplitude da resposta impulsiva (RI) do canal no instante de tempo $t, \phi_{n}(t)$ representa o deslocamento de fase provocado pelo canal e $s_{n}(t)$ denota o equivalente passa-baixas do sinal transmitido $s(t)$.

Após a eliminação da fase do desvanecimento (multiplicação de $r_{n}(t)$ por $e^{-j \phi_{n}(t)}$ ), o vetor recebido, no $n$-ésimo intervalo de sinalização, aqui denotado por $\tilde{\boldsymbol{r}}_{n}$, é expresso como

$$
\tilde{\boldsymbol{r}}_{n}=\boldsymbol{\alpha}_{n} \boldsymbol{s}_{n}+\boldsymbol{\eta}_{n}
$$




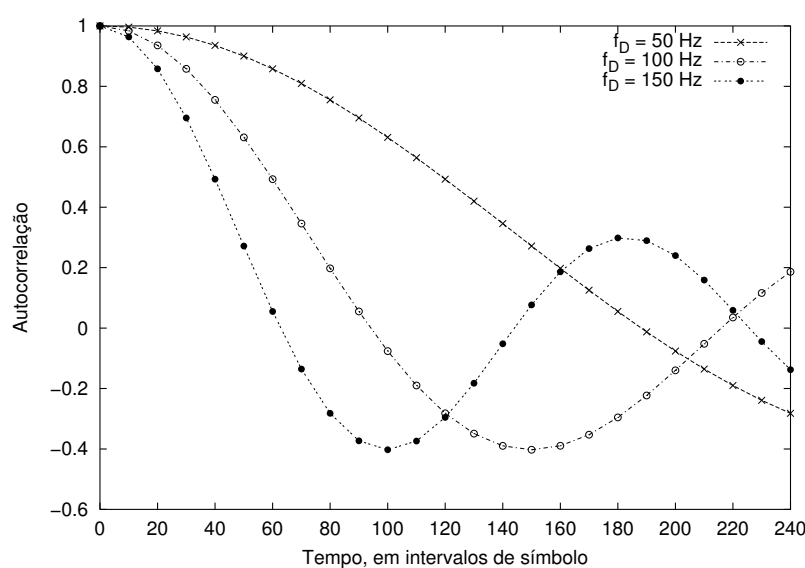

Figura 4. Função de autocorrelação do processo $\alpha(t)$ para uma freqüência de amostragem igual a 24,3 kbauds e alguns valores de freqüência Doppler $\left(f_{D}\right)$.

sendo $s_{n}$ a representação vetorial do sinal transmitido no intervalo de sinalização $n T_{s}$, dada por

$$
\boldsymbol{s}_{n}=x_{n}+j y_{n-k} \text {. }
$$

Além disso, os elementos do vetor complexo $\boldsymbol{\eta}_{n}$ são variáveis aleatórias gaussianas independentes e identicamente distribuídas (i.i.d.) com média nula e variância $N_{0} / 2$.

No receptor, depois do desentrelaçamento (Figura 3) o vetor recebido torna-se

$$
\boldsymbol{r}_{n}=\left[\alpha_{n} x_{n}+\operatorname{Re}\left\{\boldsymbol{\eta}_{n}\right\}\right]+j\left[\alpha_{n+k} y_{n}+\operatorname{Im}\left\{\boldsymbol{\eta}_{n+k}\right\}\right],
$$

em que $\operatorname{Re}\left\{\boldsymbol{\eta}_{n}\right\}$ e $\operatorname{Im}\left\{\boldsymbol{\eta}_{n+k}\right\}$ indicam as partes real e imaginária do ruído complexo $\boldsymbol{\eta}$ nos intervalos de sinalização $n T_{s}$ e $(n+k) T_{s}$, respectivamente.

Admitindo-se a transmissão de símbolos equiprováveis, o decisor ótimo, de posse das estimativas de $\left|\boldsymbol{\alpha}_{n}\right|$, calcula a distância Euclidiana quadrática entre o sinal recebido $\boldsymbol{r}_{n} \mathrm{e}$ cada um dos quatro vetores da constelação QPSK (multiplicados pelas estimativas $\left|\boldsymbol{\alpha}_{n}\right|$ e $\left|\boldsymbol{\alpha}_{n+k}\right|$ ), decidindo em favor do mais próximo a $\boldsymbol{r}_{n}$.

Considerando que o receptor seja capaz de estimar sem erro os valores de $|\boldsymbol{\alpha}(t)|$ e $\phi(t)$ e que haja descorrelação entre os valores de $\boldsymbol{\alpha}_{n}(t)$ e $\boldsymbol{\alpha}_{n+k}(t)$, mostrou-se em [15] que a probabilidade de erro de bit do sistema é minimizada para $\theta \approx \pi / 7$. Admitindo correlação entre $\boldsymbol{\alpha}_{n}$ e $\boldsymbol{\alpha}_{n+k}$, pode-se obter, a partir da função de autocorrelação do canal (Figura 4), os pontos de correlação nula que correspondem às profundidades de entrelaçamento ideais para cada caso. Desta forma, o desempenho apresentado em [15] é alcançado, caso o canal seja perfeitamente estimado.

\section{ALGORITMOS DE ESTIMAÇÃO}

$\mathrm{Na}$ técnica de diversidade em modulação, as informações de módulo e fase do canal de comunicações são utilizadas em pontos distintos no receptor, como pode ser observado na Figura 3. Em particular, a informação de fase é utilizada para compensar o deslocamento de fase provocado pelo canal. Esta operação é de fundamental importância para 114 o bom desempenho do esquema proposto pois, baseando-se em simulações previamente realizadas [21], o erro de fase compromete o correto desentrelaçamento das componentes dos sinais transmitidos. Por isto, neste trabalho, o estimador de canal é composto por dois esquemas distintos para a deteção de fase e do módulo do canal. Estes esquemas são descritos a seguir.

\subsection{O ESTIMADOR DE MÓDULO}

O algoritmo LMS (Least Mean Square) foi utilizado para obter a estimativa do módulo da resposta impulsiva do canal com desvanecimento por meio da equação recursiva [18]

$$
\hat{\boldsymbol{\alpha}}(n+1)=\hat{\boldsymbol{\alpha}}(n)+\mu \boldsymbol{s}(n) \boldsymbol{e}^{*}(n),
$$

sendo $\mu$ o passo do algoritmo e $\boldsymbol{e}(n)=\boldsymbol{r}_{n}-\hat{\boldsymbol{\alpha}}_{n} \hat{\boldsymbol{s}}(n)$. Durante o processo de treinamento $\hat{\boldsymbol{s}}(n)=\boldsymbol{s}(n)$. Após o treinamento, a estimativa desse sinal é fornecida pelo decisor.

\subsection{O ESTIMADOR DE FASE}

A estimação da fase do desvanecimento foi obtida por meio de um filtro recursivo, mais precisamente utilizou-se um PLL (Phase-Lock Loop) de 1a ordem, cuja expressão de atualização de fase é dada por

$$
\hat{\phi}(n+1)=\hat{\phi}(n)+\kappa u_{\phi}(n),
$$

em que a constante $\kappa$ é o passo (ou ganho) do filtro recursivo e $u_{\theta}(n)$ representa um detetor de erro de fase, dado por [22]

$$
u_{\phi}(n)=\operatorname{Im}\left[e^{-j \hat{\phi}(n)} \boldsymbol{s}_{n}^{*} \boldsymbol{r}_{n}\right] .
$$

O objetivo do PLL é maximizar a função de verossimilhança da fase, fazendo com que a saída do detetor de erro de fase seja nula. Apesar de sua simplicidade, a utilização deste esquema de deteção de fase levou a resultados satisfatórios, como pode ser observado na Seção 4. Uma descrição mais detalhada desse algoritmo pode ser encontrada em [22].

\section{RESULTADOS}

Nesta seção são apresentados os resultados de simulações do esquema descrito neste trabalho. Foram implementados programas em Linguagem $\mathrm{C}$ e o desempenho do sistema foi obtido segundo o Método de Monte Carlo.

\subsection{DETERMINAÇÃO DO ÂNGULO DE ROTAÇÃO ÓTIMO}

O primeiro conjunto de simulações foi realizado com intuito de determinar o ângulo de referência $\theta$ ótimo, ou seja, aquele que propicia o melhor desempenho para cada uma das constelações consideradas, a saber: QPSK, 8PSK e 16PSK. Estas constelações de referência (círculos vazios) são apresentadas na Figura 5 como também as constelações giradas (círculos cheios) em função do ângulo $\theta$. Vale a pena verificar que na constelação QPSK de referência, ao contrário das outras duas, o primeiro símbolo apresenta fase igual a $\pi / 4$. 


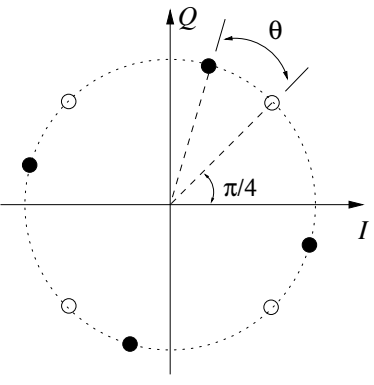

(a) QPSK.

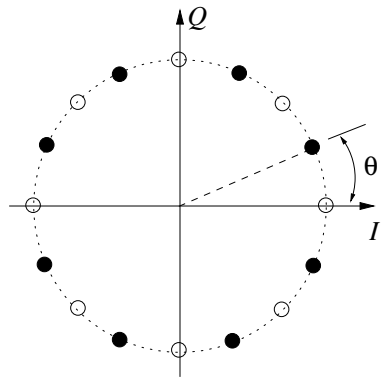

(b) 8PSK.

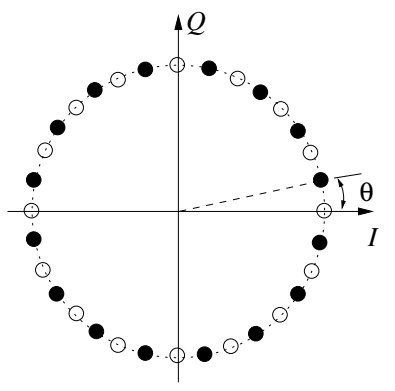

(c) 16PSK.

Figura 5. Constelações utilizadas: constelação de referência (०) e constelação girada pelo ângulo $\theta(\bullet)$.

Para cada uma das três constelações utilizadas e considerando canais descorrelacionados, foram feitas simulações medindo o desempenho, em termos da probabilidade de erro de bit, em função do ângulo de rotação $\theta$. Para cada constelação foram utilizados três valores diferentes de $E_{b} / N_{0}$ (razão entre a energia de bit e a densidade de potência do ruído). Os resultados destas simulações são apresentados nas Figuras 6, 7 e 8.

Observando as Figuras 6, 7 e 8, o ângulo ótimo (aquele que leva à menor probabilidade de erro de bit) para cada constelação foi determinado considerando a estimação perfeita de canal pelo receptor. Esses ângulos encontram-se na Tabela 1 e as Figuras 9, 10 e 11 apresentam as curvas de desempenho da técnica de diversidade em modulação em função da relação sinal-ruído do sistema. Cada uma destas figuras apresenta duas curvas: uma para a constelação de referência e outra usando o ângulo ótimo para cada constelação. Nos três casos analisados, o uso das constelações giradas pelo ângulo ótimo superam o desempenho obtido com o uso das constelações de referência. Além do mais, a partir destas mesmas figuras observa-se que o ganho em se utilizar a constelação otimizada (obtida a partir da constelação de referência por meio da rotação pelo ângulo $\theta$ ótimo) ao invés da constelação de referência é maior para o esquema QPSK. Isto decorre do fato de que quanto menos símbolos tiver a constelação, mais distantes entre si estarão as suas projeções sobre os eixos ortogonais. Por exemplo, considerando-se a probabilidade de erro de bit de $10^{-4}$, as constelações otimizadas apresentam ganhos de $14 \mathrm{~dB}, 7 \mathrm{~dB}$ e $4 \mathrm{~dB}$, em

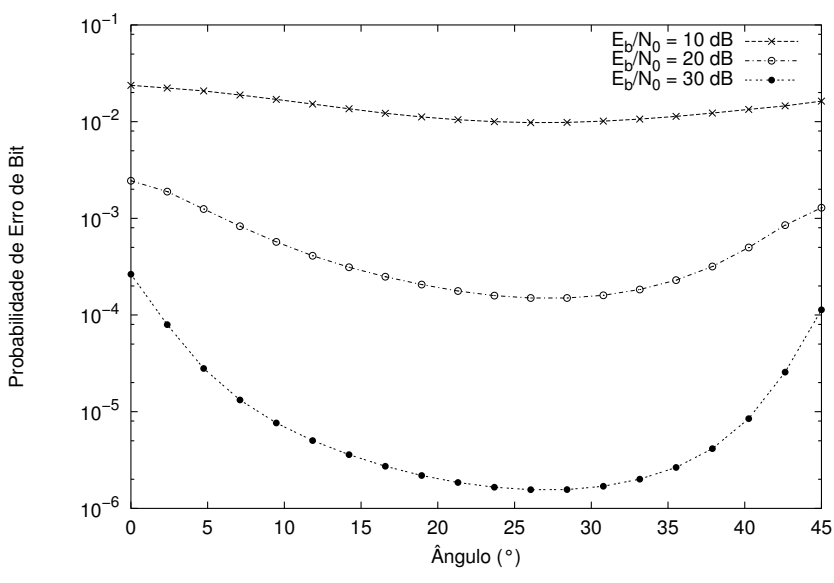

Figura 6. Probabilidade de erro de bit para o sistema proposto em função do ângulo de rotação $\theta$ para a constelação QPSK da Figura 5(a) com canal perfeitamente estimado.

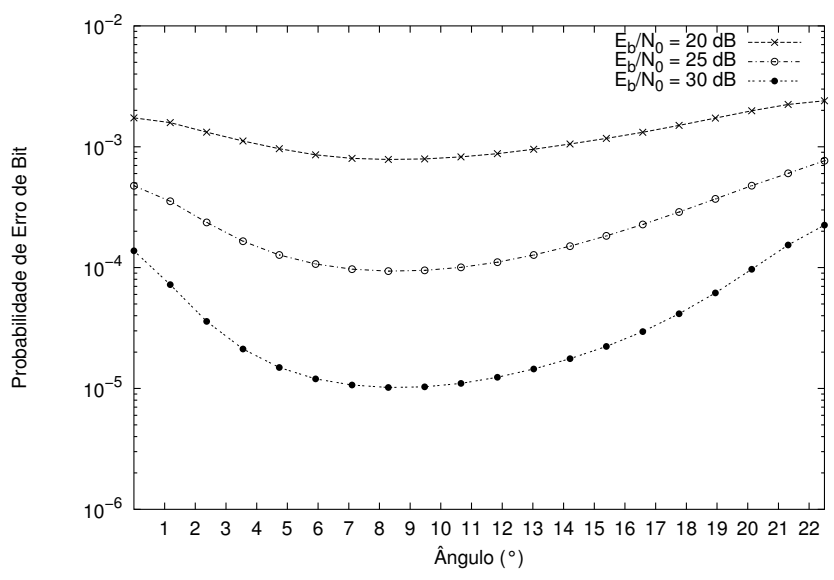

Figura 7. Probabilidade de erro de bit para o sistema proposto em função do ângulo de rotação $\theta$ para a constelação 8PSK da Figura 5(b) com canal perfeitamente estimado.

relação às constelações QPSK, 8PSK e 16PSK de referência, respectivamente.

\begin{tabular}{c|c}
\hline Constelação & Ângulo \\
\hline \hline QPSK & $27,0^{\circ}$ \\
\hline 8PSK & $8,5^{\circ}$ \\
\hline 16PSK & $4,0^{\circ}$ \\
\hline
\end{tabular}

Tabela 1. Ângulos de rotação ótimos para as constelações da Figura 5.

Em particular, considerando a constelação QPSK de referência $\left(\theta=0^{\circ}\right)$, o desempenho do esquema proposto se reduz àquele de uma transmissão QPSK convencional, cuja probabilidade de erro de bit $\left(P_{b}\right)$ também foi incluída na Figura 9 e é dada por [20]

$$
P_{b}=\frac{1}{2}\left[1-\sqrt{\frac{E_{b} / N_{0}}{1+E_{b} / N_{0}}}\right] .
$$

Observando a Figura 6 percebe-se que $\theta=0^{\circ}$ corresponde ao pior desempenho da técnica de diversidade em modulação 


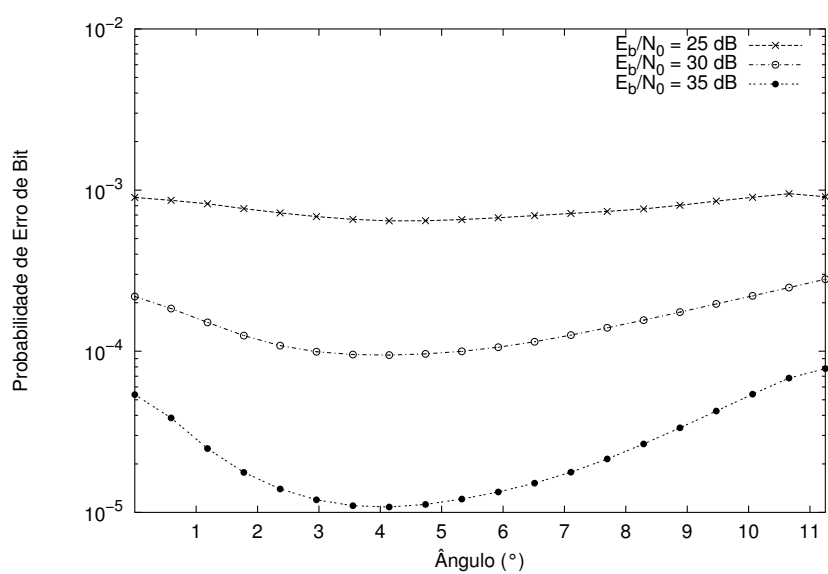

Figura 8. Probabilidade de erro de bit para o sistema proposto em função do ângulo de rotação $\theta$, para a constelação 16PSK da Figura 5(c) com canal perfeitamente estimado.

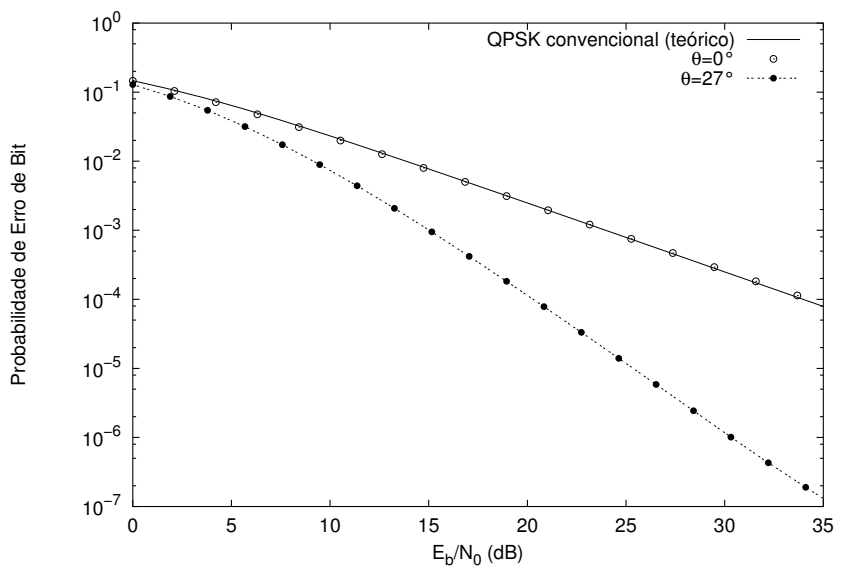

Figura 9. Probabilidade de erro de bit para o sistema proposto em função da relação sinal-ruído $\left(E_{b} / N_{0}\right)$ para a constelação QPSK da Figura 5(a) com canal perfeitamente estimado.

considerando uma constelação QPSK. Isto ocorre porque para este valor de $\theta$ não existe redundância entre as componentes em fase e em quadratura do símbolo transmitido.

Um efeito bastante interessante pode ser observado na Figura 12, na qual estão apresentados gráficos para a distribuição dos sinais no receptor após o desentrelaçamento e compensação do desvanecimento, considerando a constelação QPSK, $E_{b} / N_{0}=10 \mathrm{~dB}$ e $\theta=0^{\circ}$, $10^{\circ}, 27^{\circ}$ e $45^{\circ}$. Para cada ângulo, foram feitas 4900 transmissões de cada símbolo QPSK. Observa-se que, independentemente do valor de $\theta$, os sinais recebidos são distribuídos ao longo de eixos paralelos aos eixos principais. Nota-se também que as regiões de interferência entre os símbolos são maiores para $\theta=0^{\circ}$. Para $\theta \neq 0$, os eixos sobre os quais os símbolos QPSK encontram-se distribuídos tornamse desalinhados diminuindo a região de interferência entre os símbolos (Figuras 12(b) e 12(c)). $\operatorname{Com} \theta=45^{\circ}$ tem-se uma região de alta interferência em torno da origem, mas mesmo neste caso a interferência é menor em comparação com a interferência da constelação de referência $\left(\theta=0^{\circ}\right)$.

É importante ressaltar que esta análise qualitativa está em perfeita sintonia com os resultados da Figura 6 que apre116

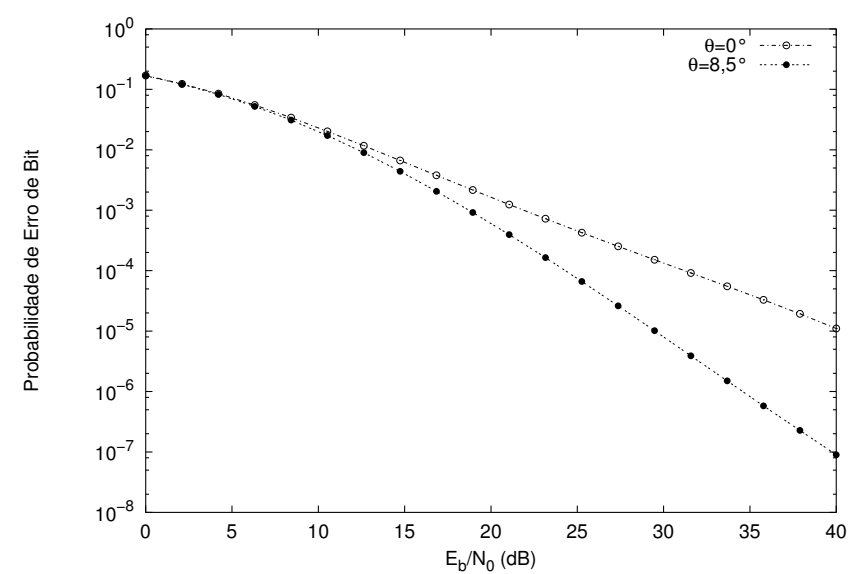

Figura 10. Probabilidade de erro de bit para o sistema proposto em função da relação sinal-ruído $\left(E_{b} / N_{0}\right)$ para a constelação 8PSK da Figura 5(b) com canal perfeitamente estimado.

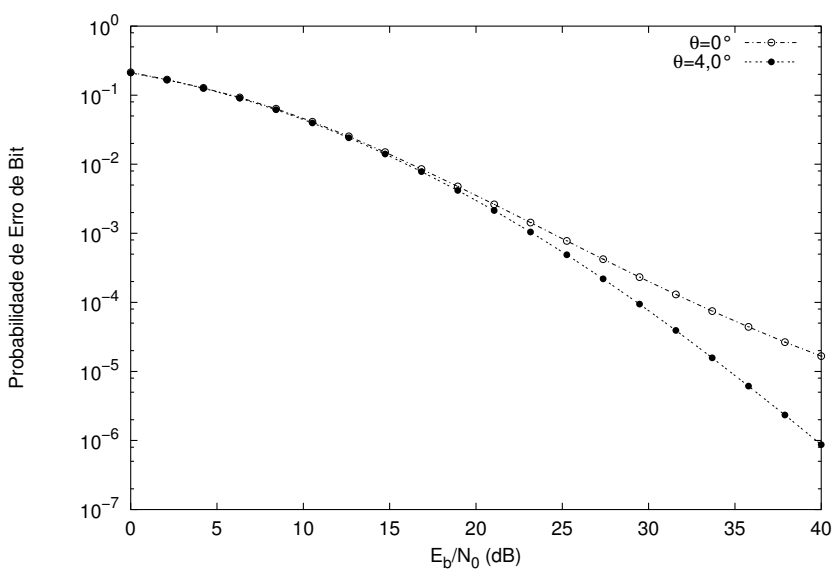

Figura 11. Probabilidade de erro de bit para o sistema proposto em função da relação sinal-ruído $\left(E_{b} / N_{0}\right)$ para a constelação 16PSK da Figura 5(c) com canal perfeitamente estimado.

senta a probabilidade de erro de bit para a constelação QPSK em função do ângulo $\theta$. O efeito ilustrado na Figura 12 foi chamado de "Efeito Roda Gigante" (Ferry-Wheel Effect) porque, independentemente do ângulo $\theta$, os símbolos permanecem distribuídos ao longo de eixos ortogonais que são paralelos os eixos principais, fato semelhante ao que ocorre com a Roda Gigante, comum em parques de diversão, que mantém os seus assentos na posição horizontal enquanto o brinquedo gira.

\subsection{INFLUÊNCIA DO ENTRELAÇAMENTO NO DESEMPENHO DO SISTEMA}

A partir da Figura 4 verifica-se que quanto menor for a freqüência Doppler $\left(f_{D}\right)$, maior deve ser a profundidade do entrelaçamento para garantir a descorrelação do canal e alcançar o desempenho máximo do sistema com o uso da técnica de diversidade em modulação. Contudo, se o desempenho do esquema proposto fosse muito sensível ao grau de correlação do canal, a aplicabilidade da técnica seria fortemente comprometida, tendo em vista o aumento nos requisi- 


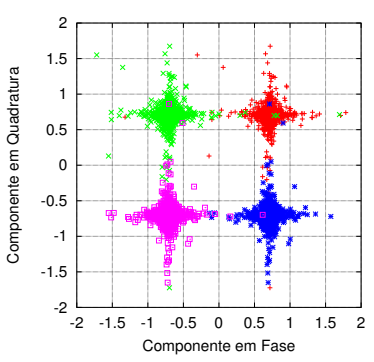

(a) $\theta=0^{\circ}$.

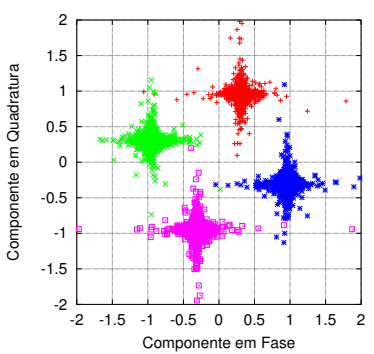

(c) $\theta=27^{\circ}$

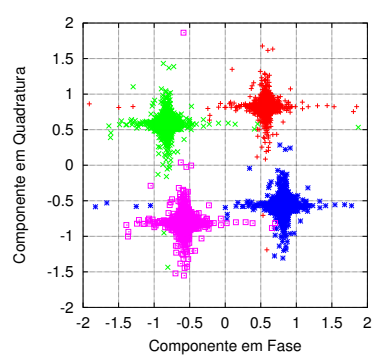

(b) $\theta=10^{\circ}$

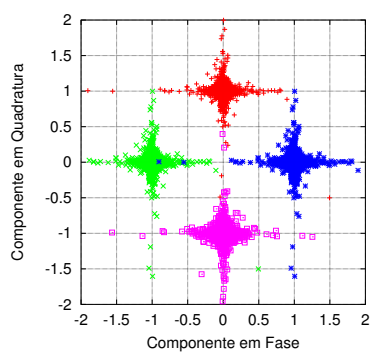

(d) $\theta=45^{\circ}$
Figura 12. Efeito Roda Gigante (Ferry-Wheel Effect). Cada gráfico representa os sinais no receptor após o desentrelaçamento e a compensação do desvanecimento. Constelação QPSK para $E_{b} / N_{0}=10 \mathrm{~dB}$ e vários valores de $\theta$.

tos de memória e de atraso no processamento. Diante disto, um segundo conjunto de simulações foi realizado para verificar o impacto da correlação de canal (medido em termos da máxima freqüência Doppler) no desempenho do sistema proposto.

Nas Figuras 13, 14 e 15 são apresentadas as curvas de probabilidade de erro de bit do sistema usando a constelação QPSK (Figura 5(a)) de referência $\left(\theta=0^{\circ}\right)$ e a constelação otimizada $\left(\theta=27^{\circ}\right)$ em função da profundidade do entrelaçamento, admitindo ausência de erros de estimação do canal e $f_{D}$ igual a $50 \mathrm{~Hz}, 100 \mathrm{~Hz}$ e $150 \mathrm{~Hz}$. Em particular, considerando uma taxa de transmissão de 24 kbauds, nota-se na Figura 4 que a curva de autocorrelação para $f_{D}=100$ $\mathrm{Hz}$ apresenta o seu primeiro zero em torno de 94 intervalos de símbolo. Contudo, de acordo com as curvas da Figura 14, percebe-se que um ganho considerável, em termos da probabilidade de erro de bit, pode ser obtido com uma profundidade de entrelaçamento de apenas 53 símbolos, ou seja, com aproximadamente $60 \%$ de correlação. Logo, para $f_{D}=100$ $\mathrm{Hz}$, a profundidade de entrelaçamento $k=53$ símbolos corresponde a uma boa solução de compromisso entre probabilidade de erro de bit e atraso para o sistema proposto. Um comportamento similar também pode ser observado para valores de freqüência Doppler iguais a $50 \mathrm{~Hz}$ e $150 \mathrm{~Hz}$ (Figuras $13 \mathrm{e}$ 15 , respectivamente) nas quais um bom desempenho pode ser atingido utilizando-se uma profundidade de entrelaçamento de apenas 105 e 35 símbolos respectivamente. Nestes casos, as profundidades ideais para o entrelaçamento são 188 e 62 símbolos, respectivamente.
Este resultado é muito importante, uma vez que garante um bom desempenho utilizando uma profundidade de entrelaçamento correspondente a apenas $60 \%$ de correlação do canal. É importante lembrar que quanto maior for a profundidade do entrelaçamento maior será o atraso introduzido na transmissão e maiores serão os requisitos de memória utilizados pelo sistema.

Observa-se também que para $\theta=0^{\circ}$ (constelação de referência), o desempenho do sistema fica insensível à profundidade do entrelaçamento pois não há redundância entre as componentes em fase e em quadratura dos símbolos transmitidos. Essas curvas também foram incluídas nas Figuras 13, 14 e 15 para fins de comparação.

\subsection{INFLUÊNCIA DOS ERROS DE ESTIMA- ÇÃO NO DESEMPENHO DO SISTEMA PROPOSTO}

Um conjunto de simulações foi realizado com o intuito de verificar o desempenho do sistema proposto empregando-se os estimadores de canal descritos na Seção 3. As simulações foram realizadas considerando as constelações QPSK de referência $\left(\theta=0^{\circ}\right)$ e otimizada $\left(\theta=27^{\circ}\right)$. Em todas as simulações utilizou-se uma freqüência de amostragem igual a 24,3 kbauds e um número mínimo de $10^{4}$ realizações do canal para cada valor de probabilidade de erro investigado. Admitindo o uso de blocos com 250 símbolos, a massa de dados mínima utilizada foi de $5 \times 10^{6}$ bits, o que garante a confiabilidade na estimação do desempenho do sistema. Para evitar a propagação dos erros de decisão, os dados foram divididos em blocos com 50 símbolos de treinamento e 200 símbolos de informação, resultando em uma vazão de $80 \%$.

Os passos dos algoritmos para estimação da fase e da amplitude foram estabelecidos, mediante simulação computacional, para cada valor de $f_{D}$ a partir das curvas de probabilidade de erro do sistema. A seguinte estratégia foi empregada na obtenção dos passos do LMS e do PLL: na determinação de $\mu$ admitiu-se estimação perfeita da fase e na determinação de $\kappa$, por outro lado, admitiu-se estimação perfeita da amplitude. É importante ressaltar que este procedimento foi efetuado para a transmissão com os dois ângulos considerados, o que permite uma comparação justa do desempenho dos esquemas investigados.

Devido à presença do ruído de gradiente [18], para um determinado valor de $f_{D}$, o valor do passo ótimo muda de acordo com o valor de $E_{b} / N_{0}$. Contudo, nas simulações realizadas utilizou-se apenas um valor de passo para cada $f_{D}$. O passo foi obtido mediante simulação computacional por meio do seguinte procedimento: Para cada valor de $f_{D}$ foram utilizados 03 valores de $E_{b} / N_{0}$ para os quais foram obtidas curvas de probabilidade de erro de bit em função do passo utilizado. A partir destas curvas, os valores de passo foram obtidos adotando-se uma solução de compromisso para a faixa de $E_{b} / N_{0}$ simulada. Os valores dos passos utilizados são apresentados nas Tabelas 2(a) e 2(b) para a constelação QPSK de referência e a constelação otimizadas, respectivamente.

Os resultados dessas simulações são apresentados nas Figuras 16, 17 e 18. As curvas foram obtidas para um entrelaçamento de 100 símbolos e considerando $f_{D}$ igual a 


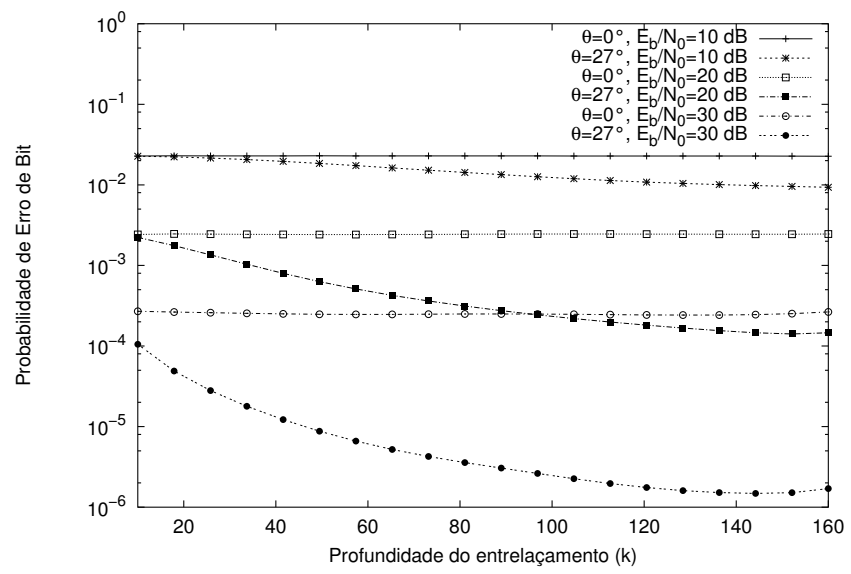

Figura 13. Probabilidade de erro de bit para o sistema proposto em função da profundidade do entrelaçamento $(k$, expresso em intervalos de símbolos) para a constelação QPSK e $f_{D}=50 \mathrm{~Hz}$.

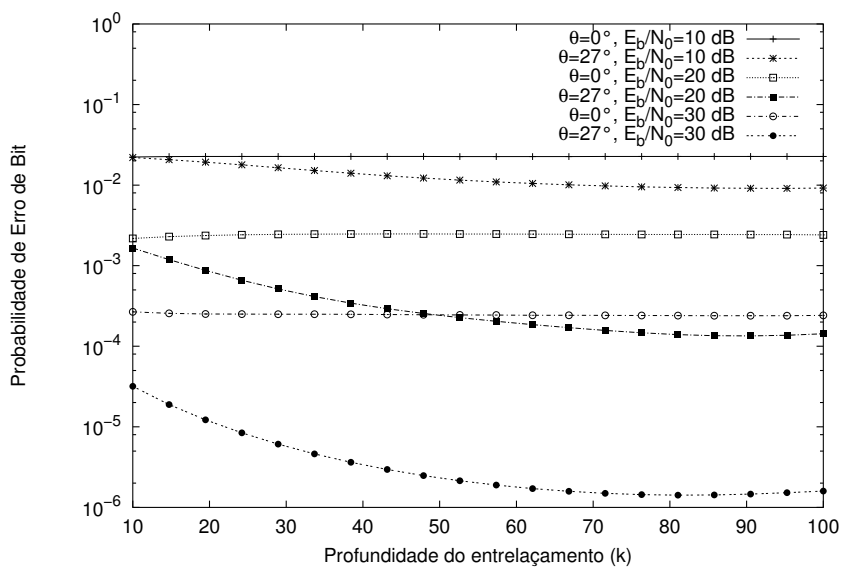

Figura 14. Probabilidade de erro de bit para o sistema proposto em função da profundidade do entrelaçamento $(k$, expresso em intervalos de símbolos) para a constelação QPSK e $f_{D}=100 \mathrm{~Hz}$.

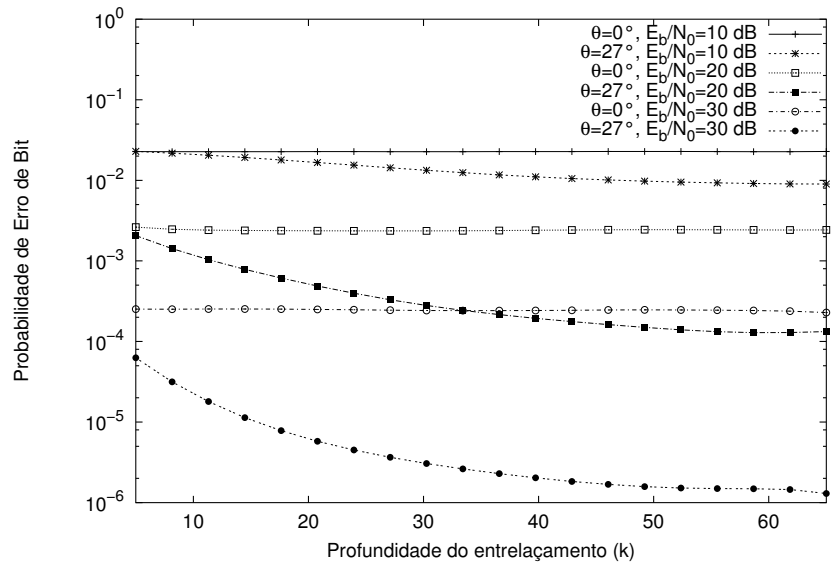

Figura 15. Probabilidade de erro de bit para o sistema proposto em função da profundidade do entrelaçamento $(k$, expresso em intervalos de símbolos) para a constelação QPSK e $f_{D}=150 \mathrm{~Hz}$

\begin{tabular}{c|c|c|c}
\hline & $f_{D}=50 \mathrm{~Hz}$ & $f_{D}=100 \mathrm{~Hz}$ & $f_{D}=150 \mathrm{~Hz}$ \\
\hline \hline$\mu$ & 0,5 & 0,5 & 0,5 \\
\hline$\kappa$ & 0,8 & 0,9 & 1,0 \\
\hline
\end{tabular}

(a) Constelação de referência $\left(\theta=0^{\circ}\right)$.

\begin{tabular}{c|c|c|c}
\hline & $f_{D}=50 \mathrm{~Hz}$ & $f_{D}=100 \mathrm{~Hz}$ & $f_{D}=150 \mathrm{~Hz}$ \\
\hline \hline$\mu$ & 0,25 & 0,4 & 0,6 \\
\hline$\kappa$ & 0,6 & 0,7 & 0,7 \\
\hline
\end{tabular}

(b) Constelação otimizada $\left(\theta=27^{\circ}\right)$.

Tabela 2. Valores de passo do LMS $(\mu)$ e do $\operatorname{PLL}(\kappa)$ utilizados nas simulações.

$50 \mathrm{~Hz}, 100 \mathrm{~Hz}$ e $150 \mathrm{~Hz}$ respectivamente. Observa-se que, em todos os casos apresentados, o desempenho do esquema com diversidade em modulação é sempre superior ao desempenho do esquema de referência.

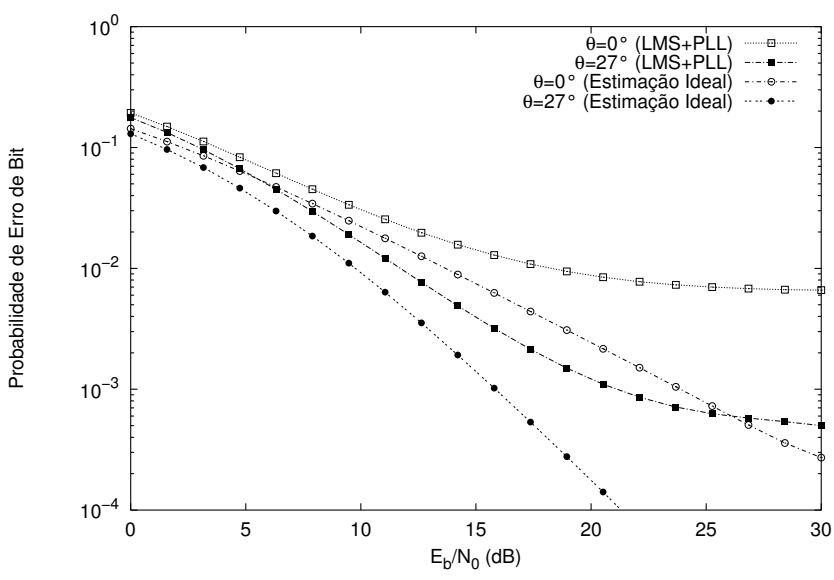

Figura 16. Probabilidade de erro de bit para o sistema proposto (Constelação QPSK) em função de $E_{b} / N_{0}$, considerando $f_{D}=50 \mathrm{~Hz}$.

Qualitativamente, os resultados apresentados nas Figuras 16, 17 e 18 são semelhantes, apresentando o efeito de probabilidade de erro irredutível (PEI), comportamento típico em canais com desvanecimento rápido, que decorrem dos erros de estimação e acompanhamento da RI do canal de comunicação. Verifica-se que o nível de probabilidade de erro irredutível aumenta à medida que se intensifica o efeito Doppler. A PEI pode ser reduzida com o uso de procedimentos de filtragem mais robustos e sofisticados, como por exemplo filtragem de Kalman [23]. Porém, em todos os casos simulados o desempenho do sistema com diversidade $\left(\theta=27^{\circ}\right)$ supera o desempenho do sistema de referência $\left(\theta=0^{\circ}\right)$, reduzindo bastante o nível de PEI para os três casos avaliados. Por exemplo, considerando-se $f_{D}=50 \mathrm{~Hz}$, o patamar de erro irredutível caiu de $7 \times 10^{-3}$ para $5 \times 10^{-4}$. Pode-se notar também, a partir desta mesma figura, que para a faixa de $E_{b} / N_{0}$ entre $6 \mathrm{~dB}$ e $25 \mathrm{~dB}$ o desempenho do sistema com constelação otimizada mesmo considerando os er- 


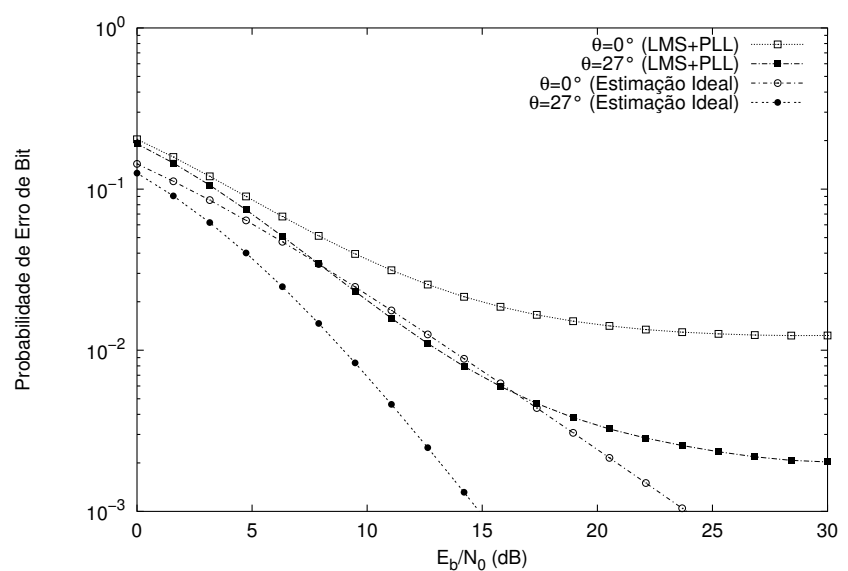

Figura 17. Probabilidade de erro de bit para o sistema proposto (Constelação QPSK) em função de $E_{b} / N_{0}$, considerando $f_{D}=100 \mathrm{~Hz}$.

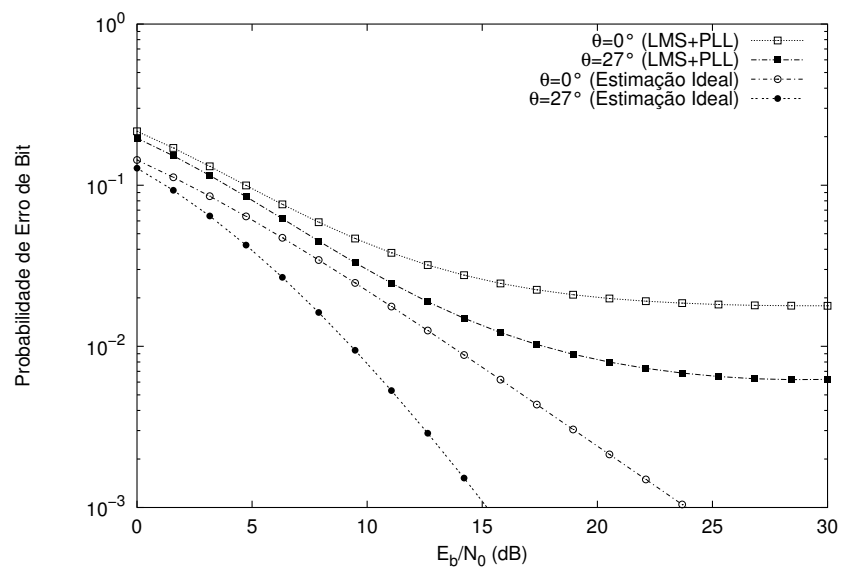

Figura 18. Probabilidade de erro de bit para o sistema proposto (Constelação QPSK) em função de $E_{b} / N_{0}$, considerando $f_{D}=150 \mathrm{~Hz}$.

ros de estimação é superior ao do sistema de referência com estimação perfeita (ausência de erros de estimação).

Pode-se observar também, a partir das Figuras 16, 17 e 18 que o desempenho do sistema, tanto para $\theta=0^{\circ}$ quanto para $\theta=27^{\circ}$, diminui com o aumento da máxima freqüência Doppler. Isto ocorre porque, para uma dada taxa de transmissão, quanto maior $f_{D}$, mais rápida é a variação do canal ao longo da transmissão. Esta característica faz com que os erros de estimação de canal, tanto em módulo quando em fase, aumentem com $f_{D}$. Em particular, observa-se que o menor ganho relativo de desempenho entre os dois esquemas ocorre para $f_{D}=150 \mathrm{~Hz}$, mostrando claramente a influência dos erros de estimação no desempenho do sistema. Contudo, vale ressaltar que mesmo para este valor de $f_{D}$, o desempenho do sistema com diversidade em modulação é superior ao do esquema de referência $\left(\theta=0^{\circ}\right)$.

As Figuras 19, 20, 21 e 22 apresentam as curvas de erro médio quadrático de estimação da amplitude e da fase da RI do canal, considerando uma relação sinal-ruído $\left(E_{b} / N_{0}\right)$ igual a $30 \mathrm{~dB}$. Conforme esperado, quanto maior o valor de $f_{D}$ maior o erro médio de acompanhamento tanto em fase quanto em amplitude. Comparando-se as Figuras 19 e 20 observa-se que o erro de acompanhamento do módulo do canal é maior para o esquema com rotação, pois neste esquema os decisores utilizados pelos estimadores operam com um total de 16 regiões de decisão enquanto que no caso do esquema de referência existem apenas 4 regiões. Com relação ao erro de fase (Figuras 21 e 22), nota-se uma pequena elevação para a constelação com otimizada $\left(\theta=27^{\circ}\right)$.

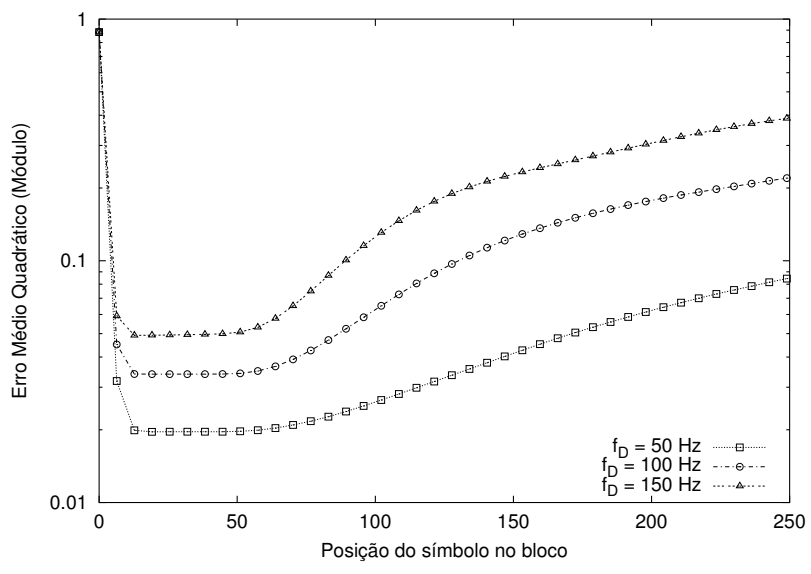

Figura 19. Erro de acompanhamento médio (Módulo) para constelação QPSK de referência $\left(\theta=0^{\circ}\right)$ considerando $E_{b} / N_{0}=30 \mathrm{~dB}$ para $f_{D}$ igual a $50 \mathrm{~Hz}, 100 \mathrm{~Hz}$ e $150 \mathrm{~Hz}$.

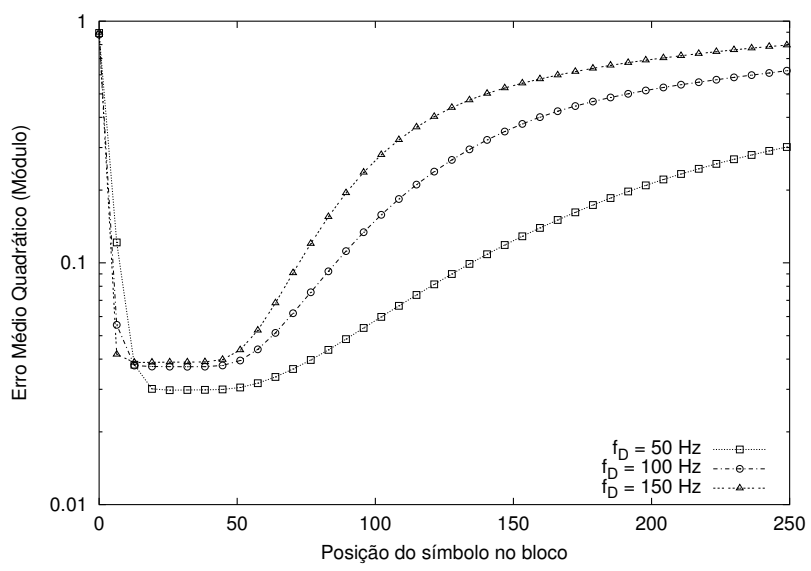

Figura 20. Erro de acompanhamento médio (Módulo) para constelação QPSK otimizada $\left(\theta=27^{\circ}\right)$ considerando $E_{b} / N_{0}=30 \mathrm{~dB}$ para $f_{D}$ igual a $50 \mathrm{~Hz}, 100 \mathrm{~Hz}$ e $150 \mathrm{~Hz}$.

\section{CONCLUSÃO}

Este trabalho apresentou uma análise de desempenho da técnica de diversidade em modulação aplicada a canais de comunicações móveis. Esta técnica combina a escolha criteriosa do ângulo de referência de uma constelação MPSK com o entrelaçamento de componentes dos símbolos antes da transmissão. A análise de desempenho foi realizada considerando que o canal de comunicação está sujeito ao desvanecimento plano e rápido. Os algoritmos de estimação 


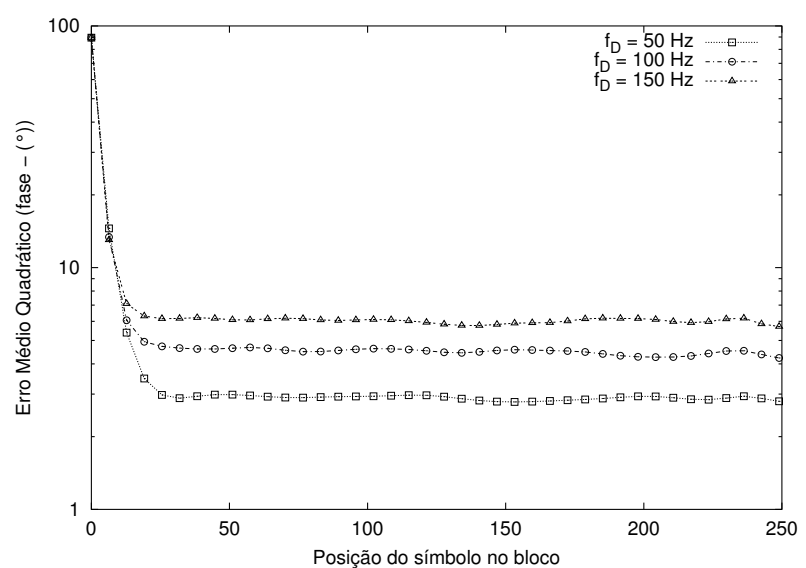

Figura 21. Erro de acompanhamento médio (Fase) para constelação QPSK de referência $\left(\theta=0^{\circ}\right)$ considerando $E_{b} / N_{0}=30 \mathrm{~dB}\left(\theta=0^{\circ}\right)$ para $f_{D}$ igual a $50 \mathrm{~Hz}, 100 \mathrm{~Hz}$ e $150 \mathrm{~Hz}$

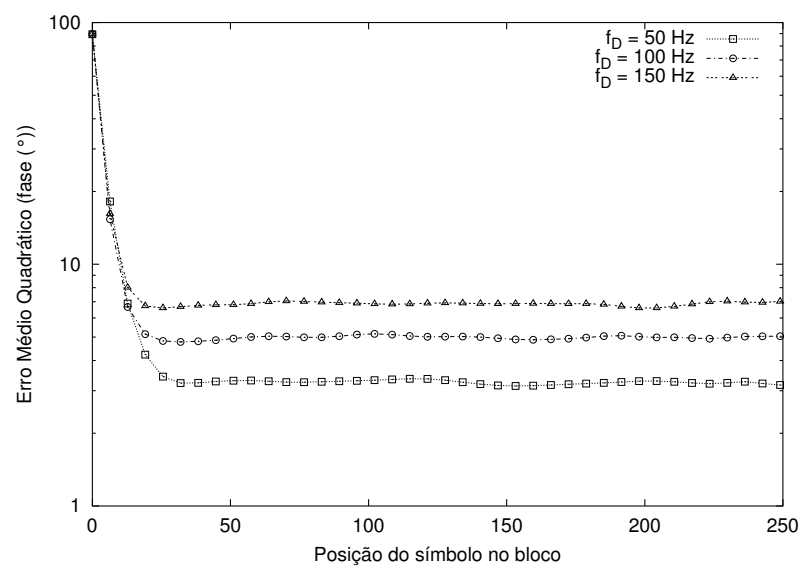

Figura 22. Erro de acompanhamento médio (Fase) para constelação QPSK otimizada $\left(\theta=27^{\circ}\right)$ considerando $E_{b} / N_{0}=30 \mathrm{~dB}$ para $f_{D}$ igual a $50 \mathrm{~Hz}, 100 \mathrm{~Hz}$ e $150 \mathrm{~Hz}$.

LMS e PLL foram utilizados para acompanhar o módulo e a fase da resposta impulsiva do canal, respectivamente.

Admitindo a ausência de erros de estimação, os ângulos ótimos de rotação (para as constelações QPSK, 8PSK e 16PSK) foram determinados e mostrou-se que a utilização destas constelações otimizadas melhora significativamente o desempenho do sistema em termos da probabilidade de erro de bit. Mostrou-se também, por meio de simulações, que o ganho de desempenho é mantido mesmo em presença de erros de estimação. Adicionalmente, foi investigado o compromisso entre a probabilidade de erro desejada e a profundidade de entrelaçamento necessária, levando em consideração o impacto do efeito Doppler no desempenho do sistema proposto. Verificou-se que uma profundidade de entrelaçamento correspondente a $60 \%$ de correlação do canal constitui uma boa solução de compromisso entre desempenho, atraso de processamento e requisitos de memória do sistema.

Como continuação deste trabalho, pretende-se investigar o comportamento do esquema proposto em canais com seletividade em freqüência e também a implementação de al- goritmos de estimação mais robustos, como por exemplo, o filtro de Kalman. Um outro ponto que pode ser abordado é a integração dos procedimentos de estimação de amplitude e fase da RI do canal, uma vez que no esquema apresentado, estes procedimentos foram realizados de forma independente.

\section{APÊNDICE}

\section{A. SIMULAÇÃO DO CANAL COM DES- VANECIMENTO PELO MÉTODO DE MONTE CARLO}

Este apêndice descreve o método de Monte Carlo usado na simulação do canal com desvanecimento.

De acordo com a técnica de Monte Carlo [24, 25], a resposta impulsiva (RI) do canal é gerada simulando o modelo físico de propagação que caracteriza o canal de comunicação. Para esta técnica, uma realização da RI do canal caracterizado pelo efeito do desvanecimento rápido e plano é dada por

$$
h(t, \tau)=\sqrt{\frac{1}{N}} \sum_{n=0}^{N-1} a_{n} \delta\left(\tau-\tau_{n}\right) e^{j 2 \pi \nu_{n} t},
$$

em que $a_{n}, \nu_{n}$ e $\tau_{n}$ são as variáveis aleatórias que representam a amplitude complexa, o deslocamento Doppler e o atraso do canal, respectivamente. Além disso, $\tau$ é o retardo na transmissão e $N$ representa a ordem do modelo que deve ser suficientemente grande para garantir que $h(t, \tau)$ seja um processo gaussiano complexo (tipicamente este valor é igual ou superior a 20).

A Equação 15 representa um modelo de canal estacionário em sentido amplo desde que as variáveis aleatórias complexas $a_{n}$ sejam estatisticamente independentes com variâncias unitárias e que o par $\left(v_{n}, \tau\right)$ seja extraído de uma função densidade de probabilidade conjunta, cuja forma é dada pela função espalhamento do canal a ser simulado [25].

As Figuras 23 e 24 apresentam respectivamente a amplitude e a fase da resposta impulsiva de uma realização do canal em função do tempo, respectivamente. As curvas foram obtidas a partir da Equação 15 considerando valores de máxima freqüência Doppler iguais a $50 \mathrm{~Hz}, 100 \mathrm{~Hz}$ e $150 \mathrm{~Hz}$, taxa de amostragem igual a 24,3 kbauds e ordem $N$ do modelo igual a 20. O tempo de observação de 40 milisegundos, o que corresponde à transmissão de 1000 símbolos. Como era de se esperar, quanto maior o valor de $f_{D}$, mais rápidas são as variações do canal, tanto em módulo quanto em fase.

\section{AGRADECIMENTOS}

Os autores gostariam de expressar os agradecimentos ao Conselho Nacional de Desenvolvimento Científico e Tecnológico (CNPq) pelo apoio financeiro e aos Professores Elvino S. Sousa e Ernesto L. Pinto pelas discussões e comentários que contribuíram para conclusão deste trabalho. 


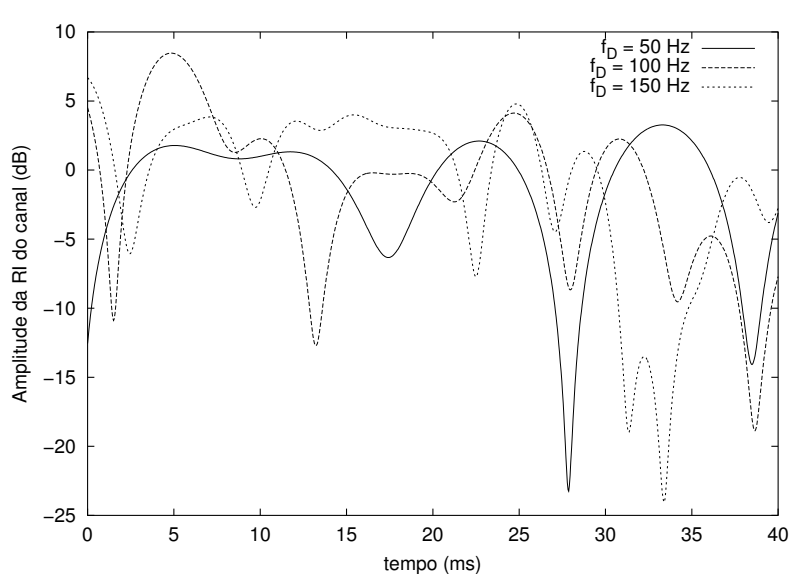

Figura 23. Amplitude da resposta impulsiva (RI) do canal com desvanecimento para três valores de freqüência Doppler $\left(f_{D}\right)$ considerando uma freqüência de amostragem igual a 24,3 kbauds.

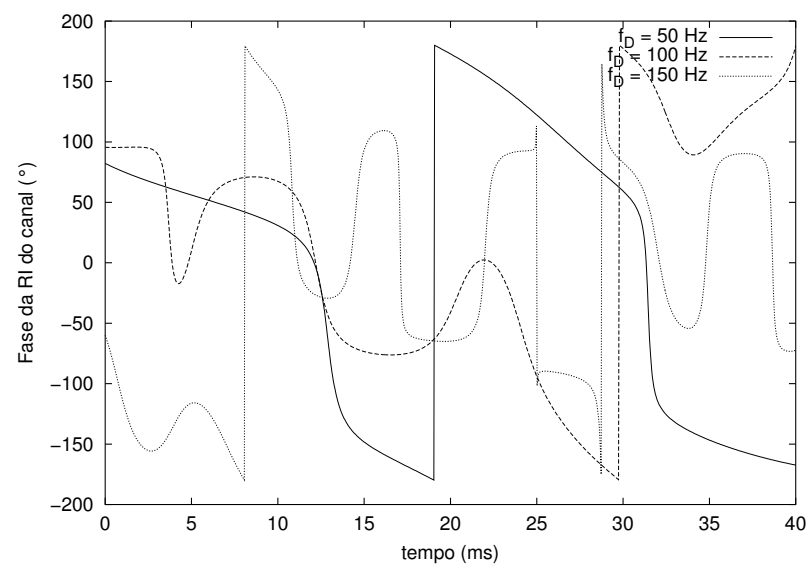

Figura 24. Fase da resposta impulsiva (RI) do canal com desvanecimento para três valores de frequiência Doppler $\left(f_{D}\right)$ considerando uma freqüência de amostragem igual a 24,3 kbauds.

\section{REFERÊNCIAS}

[1] V. M. DaSilva and E. S. Sousa. "Fading-Resistant Modulation Using Several Transmitter Antennas". IEEE Transactions on Communications, vol. 45, no. 10, pp. 1236-1244, October 1997.

[2] G. J. Foschini and M. J. Gans. "On Limits of Wireless Communications in a Fading Environment When Using Multiple Antennas". Wireless Personal Communications, vol. 6, no. 3, pp. 311-335, March 1998.

[3] V. Tarokh, N. Seshadri and A. R. Calderbank. "Space-Time Codes for High Data Rate Wireless Communication: Performance Criterion and Code Construction". IEEE Transactions on Information Theory, vol. 44, no. 2, pp. 744-765, March 1998.

[4] A. Wittneben. "A New Bandwidth Efficient Transmit Antenna Modulation Diversity Scheme for Linear Digital Communications". Proceedings of IEEE International Conference on Communications (ICC'93), pp. 1630-1634, 1993.

[5] V. Tarokh, A. Naguib, N. Seshadri and A. R. Calderbank. "Space-Time Codes for High Data Rate Wireless Communication: Performance Criteria in the Presence of Channel Esti- mation Errors, Mobility and Multiple Paths". IEEE Transactions on Communications, vol. 47, no. 2, pp. 199-207, February 1999.

[6] J. H. Winters and R. D. Gitlin. "The Impact of Antenna Diversity on the Capacity of Wireless Communications Systems". IEEE Transactions on Communications, vol. 42, no. 2/3/4, pp. 1740-1751, February/March/April 1994.

[7] N. Seshadri and C. W. Sundberg. "Multilevel Trellis Coded Modulations for the Rayleigh Fading Channel". IEEE Transactions on Communications, vol. 41, no. 9, September 1993.

[8] J. Wu and S. Lin. "Multilevel Trellis MPSK Modulation Codes for the Rayleigh Fading Channel". IEEE Transactions on Communications, vol. 41, no. 9, September 1993.

[9] M. A. Tzannes and M. C. Tzannes. "Bit-by-Bit Channel Coding Using Wavelets". Proceedings of the IEEE GLOBECOM'92, pp. 684-688, April 1992.

[10] K. J. Kerpez. "Constellations for Good Diversity Performance". IEEE Transactions on Communications, vol. 41, no. 9, pp. 1412-1421, September 1993.

[11] S. B. Slimane. "An Improved PSK Scheme for Fading Channels". IEEE Transactions on Vehicular Technology, vol. 47, no. 2, pp. 703-710, May 1998.

[12] J. Boutros and E. Viterbo. "Signal Space Diversity: A Powerand Bandwidth-Efficient Diversity Technique for the Rayleigh Fading Channel". IEEE Transactions on Information Theory, vol. 44, no. 4, pp. 1453-1467, July 1998.

[13] B. D. Jeličić and S. Roy. "Design of Trellis Coded QAM for Flat Fading and AWGN Channels". IEEE Transactions on Vehicular Technology, vol. 44, pp. 192-201, February 1995.

[14] D. Divsalar and M. K. Simon. "The Design of Trellis Coded MPSK for Fading Channels: Performance Criteria". IEEE Transactions on Communications, vol. 36, no. 9, pp. 10041012, September 1988.

[15] W. T. A. Lopes and M. S. Alencar. "Space-Time Coding Performance Improvement Using a Rotated Constellation". Anais do XVIII Simpósio Brasileiro de Telecomunicações (SBrT'2000), Gramado - RS, Brasil, Setembro 2000.

[16] J. D. Parsons. The Mobile Radio Propagation Channel. John Wiley, 1992.

[17] W. T. A. Lopes and M. S. Alencar. "Performance of a Rotated QPSK Based System in a Fading Channel Subject to Estimation Errors". Proceedings of the IEEE International Microwave and Optoelectronics Conference (IMOC'2001), pp. 27-30, Belém - PA, Brasil, Agosto 2001.

[18] S. S. Haykin. Adaptive Filter Theory. Prentice Hall, 1991.

[19] W. T. A. Lopes, J. F. Galdino e M. S. Alencar. "Desempenho de um Sistema QPSK com Rotação na Constelação em Canais com Desvanecimento Rápido Sujeito a Erros de Estimação de Canal". Anais do XIX Simpósio Brasileiro de Telecomunicações (SBrT'2001), Fortaleza - CE, Brasil, Setembro 2001.

[20] J. G. Proakis. Digital Communications. McGraw-Hill, New York, 1989.

[21] W. T. A. Lopes. "Desempenho de um Sistema QPSK com Rotação na Constelação em Canais com Desvanecimento Rápido Sujeito a Erros de Estimação de Canal”. Relatório Técnico RT00271/01, Departamento de Engenharia Elétrica, Universidade Federal da Paraíba, Campina Grande - PB, 2001.

[22] P. Koufalas. "State Variable Approach to Carrier Phase Recovery and Fine Automatic Gain Control on Flat Fading Channels". Master's thesis, University of South Australia, 1996.

[23] G. Minkler and J. Minkler. Theory and Application of Kalman Filtering. Magellan Book Company, 1993.

[24] A. G. Guimarães, C. J. A. Silva, J. F. Galdino e E. L. Pinto. "Comparação de Desempenho de Simuladores de Canais com 
Desvanecimento Rápido: Parte I - Avaliação Númerica”. Anais do XV Simpósio Brasileiro de Telecomunicações (SBT'97), pp. 426-430, Recife - PE, Setembro 1997.

[25] A. Müller. "Simulation of Multipath Fading Channels using the Monte-Carlo Method". Proceedings of the IEEE International Conference on Communications (ICC'94), pp. 15361540, 1994.

Waslon Terllizzie Araújo Lopes nasceu em Petrolina, Pernambuco, em 29 de dezembro de 1974. Recebeu o diploma de Engenheiro Eletricista e o título de Mestre em Engenharia Elétrica pela Universidade Federal da Paraíba (UFPB) em 1998 e 1999, respectivamente. É doutorando do Curso de Pós-Graduação em Engenharia Elétrica da UFPB. Suas atividades de pesquisa concentramse em quantização vetorial robusta e sistemas de comunicações sem fio. Waslon Terllizzie é membro da Sociedade Brasileira de Telecomunicações (SBrT) desde 1997.

Juraci Ferreira Galdino nasceu em Malta, Paraíba, em 1967. Formou-se em Engenharia Elétrica pela Universidade Federal da Paraíba em 1991. Formou-se Oficial Engenheiro Militar do Exército Brasileiro pelo Instituto Militar de Engenharia em 1992. Recebeu o título de mestre em Engenharia Elétrica pelo Instituto Militar de Engenharia em 1998. Desde março de 1999 é aluno de doutorado da Universidade Federal da Paraíba, Campus II, Campina Grande. Suas pesquisas concentram-se principalmente em Wavelets, filtragem adaptativa e comunicações móveis. Juraci Ferreira Galdino é membro da Sociedade Brasileira de Telecomunicações (SBrT) e do Instituto de Engenheiros Eletricistas e Eletrônicos (IEEE).
Marcelo Sampaio de Alencar nasceu em Serrita, Pernambuco, em 1957. Formou-se em Engenharia Elétrica pela Universidade Federal de Pernambuco, em 1980, recebeu o título de mestre em Engenharia Elétrica pela Universidade Federal da Paraíba (UFPB), em 1988 e o de Ph.D. em Engenharia Elétrica pela University of Waterloo, Canadá, em 1993. Desde 1984 trabalha no Departamento de Engenharia Elétrica da UFPB, onde exerce o cargo de Professor Titular. Trabalhou como consultor de diversas empresas, agências e universidades: MCI-Embratel, Telebras, TIM, Chesf, CNPq, Correios, Finep, UFPE, UFMA, CSU e Telern. Foi Diretor e atualmente é Conselheiro da Sociedade Brasileira de Telecomunicações (SBrT). É membro da Sociedade Brasileira de Microondas (SBMO), da Sociedade Brasileira de Engenharia Biomédica (SBEB) e Senior Member do Instituto dos Engenheiros Eletricistas e Eletrônicos (IEEE). Foi Professor Visitante no Departamento de Engenharia Elétrica e de Computação, Universidade de Toronto, entre julho e agosto de 1997. É revisor de diversas revistas: IEEE Transactions on Communications, IEEE Transactions on Vehicular Technology, Wireless Personal Communications, publicada pela Kluwer Academic Publishers, e Revista Brasileira de Telecomunicações, da Sociedade Brasileira de Telecomunicações. Áreas de interesse em pesquisa: Processamento de Sinais, Comunicações Ópticas, Comunicações Móveis, Efeitos Biológicos da Radiação, Teoria da Comunicação e Informação, áreas em que tem mais de 100 artigos publicados. Marcelo Sampaio de Alencar é articulista do Jornal do Commercio On Line, autor dos livros Telefonia Digital e Sistemas de Comunicações, pela Editora Érica Ltda e do livro Princípios de Comunicações, pela Editora Universitária, da UFPB. 